\title{
Kommunerna
}

\section{Självstyrelsen, makten och kompetensen}

Lars Nilsson

\section{Kommunal självstyrelse}

Det lokala självstyret brukar ofta framhållas som centralt för den svenska demokratin. Och självstyret bärs upp av kommunernas rätt att beskatta sina invånare. Det ger dem en egen ekonomi oberoende av staten. Men hur omfattande har självstyret varit? I vilka ärenden har städer, köpingar och landskommuner ansetts ha tillräcklig kunskap och kompetens för att fatta egna beslut mer eller mindre oberoende av staten och omvärlden i övrigt. Vilka personer har ansetts behöriga att delta i de kommunala valen och vilka har haft makt och inflytande över den lokalpolitiska verksamheten? Hur har man skolat de kommunalt anställda så att de kunnat utföra sina uppgifter på bästa sätt?

Den här artikeln vill belysa hur det kommunala självstyret utvecklats $i$ ett samhälle som med tiden ställt allt större krav på kunskap, kompetens och utbildning. För kommunerna med deras breda verksamhet behövs numera specialistkunskaper inom många områden. Experterna har ibland till och med kommit att uppfattats som ett hot mot den lokala demokratin. Periodvis har staten genom skärpta förordningar kring nämnder och tillsyn genom sakkunniga länsorgan sökt garantera kvaliteten i de kommunala besluten. Artikeln baseras på min tidigare forskning om kommunal utveckling, och särskilt "Kommunboken" från 201 $3 \cdot{ }^{\mathrm{I}}$ Den läsare som vill veta varifrån de enskilda uppgifterna är hämtade och vilken litteratur som anlitats hänvisas dit.

Kommunerna, som vi känner dem idag, tillkom i början av I970-talet efter omfattande sammanläggningar av mindre lokala

Hur du refererar till det här kapitlet:

Nilsson, L. 20I6. Kommunerna. Självstyrelsen, makten och kompetensen. I: Sandén, A. \& Elgán, E. (red.) Kunskapens tider: Historiska perspektiv på kunskapssambället. Pp. 62-79. Stockholm: Stockholm University Press. DOI: http://dx.doi.org/Io.I6993/bai.e. License: CC-BY 4.0 
enheter. Anledningen till denna ombildning var att det, enligt regeringen, behövdes större kommuner med fler invånare och ökad skattekraft för att man lokalt skulle kunna fullgöra sina uppgifter inom främst välfärdspolitiken och samhällsplaneringen. Folkmängd och skatteunderlag var också de faktorer regeringen utgick ifrån, när I 952 års storkommunreform planerades.

Den senaste kommunreformen startade på frivillighetens grund och med en försäkran om kommunal vetorätt. Reformförslaget blev dock starkt ifrågasatt, såväl i riksdagen som lokalt, och kunde därför genomföras först efter tvångslagstiftning. Flertalet sammanslagningar ägde rum per den I januari I97I, men vissa dröjde ytterligare tre år, till I januari I974. Antalet kommuner uppgick därefter till 278. Av de drygt 2.400 kommuner som fanns när Sveriges första kommunallagar utfärdades I 862 var det bara några få som kvarstod inom i stort sett oförändrad areal. En första omfattande reducering hade ägt rum genom storkommunreformen I952, då antalet kommuner mer än halverades.

När kommunalförordningarna tillkom på ı 860-talet fanns det betydande olikheter mellan stad och land. Man skiljde därför mellan tre typer av kommuner beroende på deras stadsmässighet. Där fanns städer blandade med köpingar och landskommuner. Olika rättsregler och olika kommunala uppgifter gällde för de tre. De mest långtgående kraven ställdes på städerna med över 3.000 invånare. Efter hand öppnades dessutom möjligheten att inom en landskommuns tätare bebyggelse bilda municipalsamhällen med viss begränsad självständighet. Uppdelningen i städer, köpingar och landskommuner kvarstod fram till I970-talet, även om den stadigt fortgående urbaniseringen gradvis suddade ut gränserna. När kommunerna blev mer likartade behövdes inte längre den gamla uppdelningen. Med I970-talets kommunreform fick vi därför rättsligt enhetliga kommuner, som kunde innehålla såväl stadsbygd som landsbygd. Alla kommuner hade nu att följa samma regelbok.

\section{Kommunalförordningarna 1862}

Genom de första kommunalförordningarna, som utfärdades I 862 och trädde ikraft I863, skedde en försiktig omfördelning av makt från staten och kyrkan till lokalsamhällets invånare. 
Städerna, utom Stockholm, fick till exempel rätten att själva välja ordförande till det nyinrättade stadsfullmäktige, och inte liksom tidigare sammanträda på allmän rådstuga inför borgmästaren. ${ }^{2}$ I Stockholm, som löd under särskild förordning, var däremot överståthållaren självskriven som ordförande. ${ }^{3}$ Borgmästaren, som utsågs av regeringen, fick visserligen delta och yttra sig på stadsfullmäktiges sammanträden, men han hade inte rösträtt. Det var dock bara i städer med minst 3.000 invånare som fullmäktige var obligatoriskt. Och endast ett drygt 30-tal städer av knappt 90 nådde sådan storlek i mitten av i 860-talet. Tillsammans representerade de bara några få procent av hela Sveriges befolkning. Många av de mindre städerna insåg snart fördelarna med ett fullmäktige och införde det på frivillig väg. Fördelarna var framförallt att man genom fullmäktige fick en mer kraftfull och beslutsför institution. Många angelägna projekt, till exempel kommunalt vatten och avlopp, renhållning och annan infrastruktur, hade tidigare fått anstå, då enighet inte kunde nås.

På landsbygden blev genom förordningarna kommunalstämman det högsta politiska organet. Fullmäktige kunde frivilligt införas, men det behövdes ny tvingande lagstiftning innan fullmäktige blev mer allmänt förekommande. Kommunalstämman gavs dock liksom stadsfullmäktige rätten att välja sin egen ordförande. I den gamla sockenstämman hade prästen varit ordförande i egenskap av sitt ämbete. Präster och borgmästare var således förlorare i den omfördelning av makt som kommunalreformen innebar.

Enligt tidens uppfattning skulle de som genom skatten mest bidrog till finansieringen av de kommunala utgifterna också ha störst makt och inflytande över besluten om medlens användning. Rösträtten var därför graderad efter inkomst och förmögenhet. Till en början fanns ingen övre gräns för hur många röster en person kunde ha, varför skillnaderna kunde bli enorma. Även kvinnor som betalade kommunalskatt hade rösträtt, liksom bolag. Och det fanns ingen åldersgräns för rösträtt. Det var penningen som räknades. Efter hand begränsades dock mängden röster per person, först till hundra och I909 infördes en 40-gradig skala. Den graderade rösträtten innebar att kommunreformens vinnare fanns bland städernas mer välbärgade borgerskap jämte landsbygdens hemmansägare. 
Intresset för de kommunala angelägenheterna var vanligen lågt i varje fall som det kommer till uttryck i valdeltagandet och närvaron på kommunalstämmor och allmänna rådstugor. Av de 20-25 procent av städernas befolkning som överhuvudtaget hade rösträtt intill sekelskiftet röstade som mest uppemot 20 procent. Men det var inte helt ovanligt med ett valdeltagande på under ıo procent. Praktiska omständigheter, som att valen förrättades under arbetstid på vardagar och nära julhelgen, bidrog knappast till att stimulera röstandet. Den graderade skalan uppmuntrade inte heller till högt valdeltagande. Först med införandet av den 40-gradiga skalan 1909 förbättrades valdeltagandet mer markant. Inkomsterna hade då också ökat så att fler personer blev röstberättigade.

Vanligen var det inte heller så många som mötte upp till sammanträdena inför borgmästaren på den allmänna rådstugan eller på kommunalstämmorna. Det krävdes ärenden utöver de vanliga för att stämmorna och rådstugorna skulle bli livligt besökta. Den sparsamma närvaron gjorde att ett fătal personer valdes och omvaldes till kommunalstämmans och kommunalnämndens ordförande och alla övriga förtroendeuppdrag. Det utmönstrades en liten elit som anförtroddes att sköta kommunens affärer. Och arbetet för det gemensammas bästa var ideellt, inga arvoden utbetalades.

Även i städerna utvecklades en styrande elit, och medlemmarna av stadsfullmäktige kunde genom omval behålla sina platser under många år. Valen till stadsfullmäktige var inledningsvis rena personval. De ledande männen inom borgerskapet träffades och kom överens om vilka som skulle kandidera och i vilken ordning de skulle stå på valsedeln. Med tiden utvecklades inom fullmäktige olika intressegrupperingar. Företrädare för investeringar i hamnen kunde till exempel ställas mot de som förespråkade satsningar på järnvägen. I andra städer kunde mer konservativt sinnade personer ställas mot liberaler, eller handlare mot hantverkare. Grupperingar av detta slag var ofta tillfälliga och kortlivade.

Ett lokalt partiväsende dröjde fram till att nationella politiska partier började bildas vid sekelskiftet I900. Partiskiljande listor kunde därefter förekomma på sina håll och konkurrera med samlingslistorna. De kommunala frågorna uppfattades dock inte som partipolitiska utan det var "stadens bästa" som gällde. 


\section{Allmän och lika rösträtt}

Med införandet av allmän och lika rösträtt för män och kvinnor inleddes en ny period med ändrad kommunal maktbalans och ökad makt åt medborgarna. I slutet av I9 8 antog riksdagen det framlagda förslaget till kommunal rösträttsreform. För att få rösta krävdes förutom svenskt medborgarskap, att man var 23 år, myndig och ostraffad. Man skulle också ha betalt sin kommunalskatt och fick inte vara omhändertagen för fattigvård.

De första kommunalvalen för män och kvinnor, enligt den nya ordningen, ägde rum redan på våren I9I9. Då hade också gränsen för fullmäktiges införande sänkts från 3.000 till I.500 invånare och den tillämpades för såväl städer och köpingar som landskommuner. Flera småstäder hade redan frivilligt infört fullmäktige. Endast Skanör-Falsterbo behöll rådstugan efter I9I9. Ungefär en tredjedel av de cirka 2.400 landskommunerna var så befolkningsrika att fullmäktige var obligatoriskt. Andra bytte frivilligt från stämma till fullmäktige.

År I93 8 sänktes gränsen för obligatoriskt fullmäktige till 700 invånare. Efter storkommunreformens genomförande 1952 var det bara en enda landskommun, Holmön, som kunde behålla stämman. Och den möjligheten försvann I955, när en ny kommunallag trädde ikraft.

Valdeltagandet ökade genom rösträttsreformen I9I9 till över 60 procent i städerna men med stora lokala variationer. Och i det närmast följande valet sjönk deltagandet kraftigt. Det dröjde till I930-talet innan man var tillbaka på 60-procentsnivån. Därefter steg deltagandet i valen till stadsfullmäktige gradvis upp till 80 procent på I950- och I960-talen. På landsbygden var valdeltagandet inledningsvis lägre än i städerna. Utvecklingsförloppet var dock detsamma med låga siffror under I920-talet. Och i slutet av I950-talet hade landskommunerna kommit ikapp städerna ifråga om valdeltagande. De lokala variationerna har samtidigt varit framträdande såväl i stad som på land.

De kommunala valen ägde ännu inte rum samtidigt som valen till riksdagens andra kammare, inte ens samma år. Däremot hölls från I93 8 landstingsval samtidigt med kommunalvalen. De partier som tävlade om platser i stadsfullmäktige var inte riktigt 
desamma som i andrakammarvalen. Samlingslistor var till exempel länge gängse förekommande för de borgerliga kandidaterna och ibland kunde även socialdemokrater och kommunister ingå. Annars var det bara de två senare partierna som deltog med egna partilistor. Det förekom i de första kommunalvalen att alla ledamöter valdes in från en enda gemensam lista. Lokala partier var inte alldeles ovanligt. På I920- och I930-talen fanns i stadsfullmäktige 70-80 rent lokala partier fördelade på 20-30 städer. Flera städer hade således mer än ett lokalt parti. Det var dock bara några få procent av mandaten som tillföll de lokala partierna.

När de valda ledamöterna till stadsfullmäktige fördelas på de partier som var representerade i andrakammaren fick högerpartiet vid valet I9I9 en knapp övervikt över socialdemokraterna. Resultatet överraskade samtiden, då många väntat sig en mycket kraftigare framryckning för socialdemokraterna och vänstersocialisterna. Och vid de närmast följande kommunalvalen stärkte högern sin ställning. Men vid valet I 926/27 började en period av socialdemokratiska framgångar. Efter kommunvalet 1938 hade partiet egen majoritet i mer än hälften av alla stadsfullmäktige och var största parti i nästan varje enskild stad. Den dominansen bestod fram till I966. Endast ett fåtal städer hade således fram tills dess borgerlig övervikt i stadsfullmäktige.

Oavsett valresultaten var samlingsstyre vanligt förekommande. De socialdemokratiska valframgångarna på I920- och I930-talen följdes således inte av något omedelbart maktskifte i stadsfullmäktige. Det var inte ovanligt att borgerliga ordföranden i stadsfullmäktige, drätselkammare och andra viktiga nämnder satt kvar på sina poster även efter valförluster. På motsvarande sätt kunde städer med fortsatt borgerlig majoritet släppa fram socialdemokrater till tunga uppdrag efter valframgångar för arbetarpartier. Det kommunala samlingsstyret fortsatte i princip fram till I970-talet även om det började luckras upp under I950- och I960-talen.

Samlingslistor var länge vanliga i landskommunerna. Där förekom till en början inte heller alltid konkurrerande listor utan alla som kandiderade var uppförda på en gemensam lista. Partiväsendet trängde dock så småningom in även i landskommunerna och från I950 års kommunalval är ledamöterna fördelade efter partier i 
den officiella statistiken. Samlingsstyre var dock fortsatt vanligt ända fram till I970-talet.

Samtidigt skiftade förhållandena starkt mellan olika landskommuner och olika delar av Sverige. I köpingarna, liksom i städerna, var socialdemokraterna med eller utan stöd av kommunisterna i majoritet. När valresultaten för alla landskommuner summerades fick de borgerliga partierna flertalet mandat till följd av bondeförbundets starka ställning. Men det fanns stora lokala skillnader mellan till exempel bruksorter och jordbruksbygder.

\section{Enhetskommunen}

Genom den kommunreform som trädde ikraft I januari I97I fick Sverige rättsligt enhetliga kommuner. Den tidigare uppdelningen i städer, köpingar och landskommuner upphörde att gälla. Samtidigt minskades antalet kommuner på nytt ordentligt genom sammanslagningar. Efter de sista sammanläggningarna I974 bestod Sverige av 278 kommuner. Antalet har därefter ökat till dagens 290. En kritik mot reformen var att den hotade den lokala demokratin genom den kraftiga reduceringen av antalet förtroendevalda. Allt färre skulle sköta allt mer. Med olika medel som till exempel kommundelsnämnder har man senare försökt bemöta oron för demokratiskt underskott.

Den partipolitisering av det kommunala livet som inleddes efter storkommunreformen I 952 förstärktes nu. Samlingslistorna försvann och ersattes genomgående av partilistor. Valdagen blev gemensam för val till riksdagen, landstingen och kommunerna. Det kallades för det kommunala sambandet och ansågs av många som angeläget att upprätthålla. Likaså upphörde samlingsstyret av det gamla slaget. Istället infördes en form av majoritetsstyre, vanligen kallat samlingsstyre med majoritetsmarkering. Det innebär att det eller de största partierna tillsätter alla ordförandeposter. Kommunerna blev miniatyrer av riksdagen. Partierna var dock fortfarande inte helt desamma lokalt som nationellt.

Fram till I960-talet fanns ofta bara tre större partier i stadsfullmäktige: högern, folkpartiet och socialdemokraterna. I vissa, främst norrländska städer, kunde kommunisterna vinna framgångar, men fick i övrigt mest enstaka mandat. På landsbygden 
tillkom bondeförbundet, senare centerpartiet. Därefter har partierna blivit många fler genom tillkomsten av Kristdemokraterna, Miljöpartiet, Ny Demokrati och Sverigedemokraterna.

Till dessa nationella partier kommer så alla de lokala partier som bara ställt upp i den egna kommunen. De har med åren blivit allt fler. Idag har ungefär hälften av alla kommuner ett eller flera rent lokala partier representerade i fullmäktige. Den tilltagande mängden av partier har inneburit att det ofta varit svårt att finna starka majoriteter. Samverkan mellan två eller flera partier har visat sig nödvändigt. Små partier har på så sätt kunnat få inflytande långt utöver vad deras andel av väljarkåren berättigat till. Påtvingad samverkan av detta slag är dock något annat än det frivilliga samlingsstyre, utan majoritetsmarkering, som tidigare praktiserades. Partipolitiseringen av det kommunala livet har mer eller mindre omöjliggjort den formen av samlingsstyre. Istället har blockstyre tillsammans med mångstyre blivit vanligt förekommande.

Varje enskild kommun består i dag av en blandning av tätorter och glesbygd. I den tidigare indelningen, med städer, köpingar och landskommuner, var den politiska uppställningen enkel. Generellt var städerna och köpingarna röda och landsbygden blå. I kommunvalen efter I970 har de politiska majoriteterna ständigt skiftat mellan de två stora blocken. En försmak gav kommunalvalet I966 med stora borgerliga framgångar, och särskilt för centerpartiet, i städerna.

Kommunala förtroendeuppdrag är inte längre ett ideellt och oavlönat arbete. År I9I 3 fick kommunerna rätt att arvodera de tyngre och mer arbetsamma uppdragen. Även traktamenten och reseersättningar kunde utgå i vissa fall efter länsstyrelsens medgivande. Arvoden blev efter hand allt vanligare och med början i de större städerna övergick man så småningom till att arvodera politiker på heltid eller deltid. Det var åtminstone till viss del förorsakat av vad som uppfattades som ett ökat tjänstemannavälde över de kommunala besluten. Genom arvoden på hel- eller deltid ville man stärka fullmäktiges och de förtroendevaldas ställning i den kommunala beslutsprocessen.

Vid övergången till enhetskommuner i början av I970-talet hade nästan alla kommuner minst en heltidsarvoderad politiker, 
och i flera fall mer än en. Trots det kunde tjänstemännens inflytande ibland upplevas som alltför stort. När marknads- och managementreformerna blommade upp på I990-talet ökade dessutom delegeringen av beslut från politiker till tjänstemän. De folkvalda gavs en mer kontrollerande och övervakande roll.

\section{Det kommunala uppdraget}

De första kommunalförordningarna angav bara helt kort att kommunens uppgift var att sköta gemensamma ordnings- och hushållningsfrågor. Men det fanns också annan lagstiftning som lokala myndigheter var underställda, som till exempel folkskolestadgan och fattigvårdsförordningarna. Folkskolan var dock länge en kyrklig och inte en kommunal uppgift. Med början i de större städerna skedde under I900-talet en successiv överföring av folkskolan från kyrkan till kommunen. Det dröjde dock fram till mitten av I950-talet innan det juridiska bandet mellan kyrka och folkskola helt upplöstes. Då var det bara i tolv kommuner som kyrkan fortfarande var huvudman för folkskolan.

För landskommunernas del var fattigvården till en början den klart viktigaste och mest kostsamma uppgiften. Folkskolan drog dock ofta högre kostnader än fattigvården, varför kyrkans budget var större än kommunens. I städerna var bilden en helt annan. Där användes en stor del av skatteintäkterna till förbättringar och utbyggnader av den fysiska infrastrukturen. Det handlade till exempel om vatten, avlopp, renhållning, gator, vägar, parker, brandförsvar, kommunala byggnader, hamnar och lokaltrafik. Utläggen för fattigvård och folkskola kunde per person vara väl så höga som på landet, men de utgjorde likväl en mindre del av budgeten.

De kommunala uppgifterna förändrades med tiden genom bland annat urbaniseringen och politiska beslut i riksdagen. Kommunerna fick till exempel ansvaret att bygga välfärdssamhället. För städernas del innebar det att skola, vård och omsorg tog allt större resurser i anspråk, varför den fysiska infrastrukturens andel av budgeten minskade. På landsbygden var det tvärtom. Till följd av den fortgående urbaniseringen ökade investeringarna $\mathrm{i}$ den fysiska infrastrukturen mer än vad kostnaderna för skola, vård och omsorg gjorde. 
Samtidigt som staten gav kommunerna i uppdrag att bygga välfärdssamhället eller folkhemmet ökade också den statliga kontrollen. Nya lagar och förordningar som reglerade och begränsade de kommunala friheterna utfärdades. Det gällde till exempel nämndorganisationen och sammansättningen av kommunala nämnder. Minst en kvinna skulle till exempel ingå i barnavårds- respektive nykterhetsnämnden. Redan tidigare fanns krav på en eller flera sakkunniga ledamöter i bland annat byggnadsoch hälsovårdsnämnderna. Länsstyrelserna fick i uppdrag att se till att kommunerna tog sitt ansvar för välfärdsbygget. Inom varje län skulle organ som bland andra länsnykterhetsnämnd, länsskolnämnd och länsbostadsnämnd inrättas. Den ökade kommunala självständighet som de första kommunalförordningarna innebar tycks nu ha inskränkts till förmån för den statliga auktoriteten.

Bilden är dock inte helt entydig. När kommunernas makt över skolan minskade genom länsskolnämndernas tillkomst I958 fick de å andra sidan ansvar för all skolverksamhet i kommunen och inte bara folkskolan. Vidare gav det kommunala planmonopolet ( I947) kommunerna själva rätten att bestämma vad som skulle byggas och var i kommunen det skulle ske. Efterkrigstidens sociala bostadsprogram gav också särskilda fördelar för kommunala bostadsbolag och stiftelser. Kommunal näringspolitik var däremot inte tillåten och inte heller konkurrens mellan kommuner. Kommuner i ekonomisk kris kunde istället vända sig till staten och begära hjälp.

Uppgifter har dessutom flyttats från landstingen till kommunerna. Reformer inom socialvården i början av I990-talet gav således kommunerna ensamma ett samlat ansvar för långvarig service, vård och omsorg av äldre, sjuka och handikappade. En större överföring tog vägen från kommunerna till staten. Det gällde polis-, åklagar- och exekutionsväsendet som förstatligades I965. Åtgärden var en följd av samhällsutvecklingen i stort som till exempel urbaniseringen, växande bilism, ny typ av brottslighet, polisens alltmer komplicerade tekniska utrustning och en förändrad syn på polisarbetet.

Den nyliberalism som växte fram mot slutet av ı 900-talet som en reaktion mot tidigare vänstervindar innebar till viss del ökad kommunal självständighet gentemot staten. Men bilden är åter 
splittrad. Ökad kommunal frihet på ett håll balanseras av minskad självständighet på ett annat. Med 1977 års kommunallag ersatte mål- och resultatstyrning i princip den tidigare statliga detaljregleringen av kommunerna. Inom skolan och socialtjänsten kvarstod dock detaljstyrningen, och inom andra områden tycks den åter ha ökat mot seklets slut. Statsbidrag kunde ges mer generellt än tidigare vilket inte hindrade att riktade bidrag periodvis ökade i omfattning.

De olika länsorgan som funnits för att övervaka och assistera kommunerna avvecklades successivt. Länsskolnämnderna upplöstes till exempel I99I, vilket brukar kallas för "skolans kommunalisering". Det som upphörde var således den statliga tillsynen via länsnämnderna. Ansvaret för skolan har dock alltid varit lokalt alltsedan den första folkskoleförordningen I 842, först kyrkan och senare den borgerliga kommunen. Länsbostadsnämnderna fanns kvar till I993, medan länsnykterhetsnämnderna lades ned I98I.

Genom I99I års kommunallag blev det tillåtet för varje enskild kommun att själv bestämma över sin nämndorganisation. Samtidigt utökades rätten att delegera beslut. Enligt tidens uppfattning skulle kommuner skötas som privata företag. Privatiseringar av kommunal verksamhet och konkurrensutsättning blev därmed allt vanligare. All kommunal verksamhet som inte innebar myndighetsutövning skulle i princip upphandlas i konkurrens mellan privata aktörer och kommunala förvaltningar. Den kommunala verksamheten kom att ändra karaktär. Allt mindre resurser avsattes till fysisk infrastruktur, när kommunala bolag och privata företag tog över ansvaret. Skola, vård och omsorg blev istället de största posterna i den kommunala budgeten. Och kommunerna finansierade även upphandlad privat verksamhet inom dessa och andra områden. Många ärenden som kommunerna själva tidigare beslutat om, och som handlagts av kommunala tjänstemän, övergick nu i privata händer. Det kan ses som en självpåtagen inskränkning av den kommunala kompetensen till förmån för den privata sektorn.

Konkurrens skulle också råda mellan kommuner. Staten till och med uppmuntrade kommuner att tävla mot varandra. Tidigare restriktioner mot kommunal marknadsföring och kommunalt stöd till privata företag övergavs under I970- och I980-talens ekonomiska besvärligheter, när staten inte längre på samma sätt 
som förr kunde hjälpa krisande kommuner. Nu fick var och en söka rädda sig själv genom egna åtgärder. Kommunala näringslivsorgan och marknadsföringsinsatser, som dessförinnan inte varit tillåtna, blev nu legio. Nya slogans och logotyper antogs. Den egna kommunen skulle, som det så gärna framställdes, "sättas på kartan", vad man nu menade med det.

Någon ny reform med ytterligare reducering av antalet kommuner har inte varit aktuell. Reformerna har istället riktats mot länen och landstingen som i några fall ombildats till regioner. För kommunerna har samarbete varit nyckelordet. Och det har gällt samverkan inte bara med andra kommuner utan även partnerskap med landsting, län, föreningar, privata företag med flera, i form av till exempel projekt och nätverk. På så sätt har nya gemensamheter bildats för att bland annat stärka regionala identiteter. Samtidigt tycks möjligheterna till offentlig kontroll av och insyn i sådana nya samarbetsorgan ibland vara begränsade.

\section{De kommunalt anställda}

De svenska kommunerna sysselsatte 2013 nästan 800.000 personer och därtill kom landstingen med uppemot 250.000 anställda. Av alla förvärvsarbetande i hela riket svarade kommuner och landsting för över 20 procent. Kvinnorna var i klar övervikt och uppgick till ungefär 80 procent av samtliga sysselsatta. Andelen var densamma för såväl kommuner som landsting. Det kan jämföras med ett genomsnitt på strax under 50 procent kvinnor på hela arbetsmarknaden. Kvinnorna fanns till stor del inom sjukoch hälsovården, förskolorna, hemtjänsten, äldreomsorgen och socialtjänsten.

Bakom sifforna finns en mångfald av yrken med mycket skiftande krav på boklig skolning. Vissa tjänster kräver akademisk examen och visad yrkeskompetens. I andra fall, bland annat inom vård och omsorg, ställs ibland rätt låga krav på utbildning. De arbetsuppgifter med låga utbildningskrav, som förr utfördes av gatu- park- och renhållningsarbetare med flera är numera ofta utlagda på privata entreprenörer och personerna ifråga därmed inte längre kommunalt anställda. Så kan det också vara inom till exempel hemtjänsten. 
Jämfört med dagens förhållanden framstår I 80o-talets kommunala förvaltning som tämligen enkel och okomplicerad. I landskommunerna förväntades de folkvalda själva sköta administrationen. De anställde barnmorskor och folkskollärare efter att kommunen tagit över ansvaret för skolan. De skötte taxering och bokföring, utbetalningen av fattigvård och löner, skrev protokollen och mycket mer därtill. Ordföranden hade kommunalkontoret "på fickan". Det var nog inte helt ovanligt att hustrurna ryckte in och hjälpte till med kontorsarbetet.

I takt med växande arbetsbörda blev det nödvändigt att med kommunens medel avlöna sekreterarhjälp eller kontorsbiträden. Kommunalkamrer blev efterhand en viktig post och den ledande tjänstemannen i landskommunerna med ansvar för bland annat den kommunala bokföringen, skatteindrivningen och budgeten. Sådana tjänster började tillkomma kring sekelskiftet I900, blev allt vanligare efter I920, allmänt förekommande mot slutet av I940-talet för att försvinna genom I970-talets kommunreform. Arbetsuppgifterna togs då över av andra med ansvar för den kommunala ekonomin.

I städerna var förhållandena annorlunda. Deras större folkmängd och mer omfattande kommunala uppgifter medförde tidigt visst behov av förvaltning och administration, men också av manuella yrken. Kommunalarbetare anställdes för gatuarbeten, renhållning, parkskötsel, de kommunala tekniska verken med mera. Poliser upprätthöll ordningen. Arkitekter, ingenjörer och andra yrkesutbildade anlitades för stadsplanering och stadsbyggande och all annan infrastruktur. För att inhämta den senaste kunskapen inom till exempel vatten, avlopp och renhållning kunde betrodda högre tjänstemän sändas på studieresor till tyska, brittiska eller andra utländska städer.

Svenska Fattigvårdsförbundet och Centralförbundet för socialt arbete (CSA) ordnade redan kring sekelskiftet I 900 kurser för yrkesmässig utbildning inom det sociala området. Det gällde bland annat diakonissor och föreståndare för ålderdomshem och barnhem. En mer allsidig utbildning av socialarbetare startade CSA I9 Io och studietiden ökade efterhand upp till ett och ett halvt år. För de som ägnade sig åt den kommunala förvaltningen fanns vid den tiden ingen motsvarande utbildning. Uppfattningen att arbetet för det gemensammas bästa var av ideell natur stod stark. 
Ännu i I930 års kommunallag stadgades till exempel att kommunalnämnden utser kassaförvaltare inom sig. Akademiskt skolad personal förekom bara på de större städernas avlöningslistor och var inte vanligt där heller.

Behoven av mer utbildad personal ökade i takt med urbaniseringen och nya statliga krav på kommunerna. Genom sina intresseorganisationer började både kommuner och landsting med kursverksamhet på I920-talet. Landskommunernas förbund arrangerade sin första kommunalkurs 1924 i Sundsvall. Den följdes omedelbart av nya kurser på andra orter runt om i Sverige. Landstingsförbundet var dock först med kursgivningen genom den sysslomanskurs man ordnade i Stockholm I923. Liknande kurser följde I932 och I 942.

Stadsförbundet valde en annan väg och engagerade sig i bildandet av Institutet för socialpolitisk och kommunal utbildning och forskning. Verksamheten startade I92 I i Stockholm och syftet var att ge högskolekompetens åt studerande som ville ägna sitt yrkesliv åt socialvård och kommunalförvaltning. På I 940-talet tillkom socialinstitut i Göteborg och Lund och 1962 i Umeå. Instituten omvandlades till socialhögskolor I964 och utbildningen förlängdes samtidigt. Strax därefter fick Örebro och Östersund socialhögskolor. Genom högskolereformen 1977 inordnades de dittills självständiga socialhögskolorna under universiteten som institutioner för socialt arbete.

Många kommunaltjänstemän har genom åren fått sin utbildning vid socialhögskolorna och deras föregångare. Socialsekreterare och kommunalkamrerare är två exempel på yrken med examen från skolornas sociala gren respektive förvaltningslinje. En annan akademisk väg in på den kommunala arbetsmarknaden kunde vara genom en pol. mag. examen. Den utbildningen infördes I935. Statskontorets utbildningar har också varit inriktade mot dem som velat göra en karriär inom offentlig förvaltning. Andra former av akademiska examina har naturligtvis också förekommit bland den kommunala personalen. Inom stadsbyggnad, planering, parker och annan infrastruktur har det till exempel efterfrågats arkitekter, ingenjörer och andra yrkesutbildade personer.

För Stadsförbundets del var det således viktigt att stärka de kommunalanställdas akademiska kompetens. I landskommunerna var 
uppgifterna inte av den arten att de krävde akademisk examen. Landskommunernas förbund valde därför att utbilda och vidareutbilda medlemmarnas personal via återkommande kurser. Förbundet startade även blankett- och förlagsverksamhet på I920-talet. Genom standardiserade blanketter och räkenskapsböcker kunde arbetet på kommunalkontoren underlättas och skapa bättre ordning inom den ekonomiska redovisningen. Vidare utgav förlaget bland annat handböcker och lagtexter i syfte att underlätta kommunalmännens arbete.

Förbunden anställde efterhand konsulenter som medlemmarna kunde få råd av. Vissa konsulenter tycks ständigt ha varit på resande fot och besökt medlem efter medlem. Utredningsuppdrag kunde likaså beställas och utföras av förbundens experter. Genom sina tidskrifter informerade förbunden medlemmarna fortlöpande om utvecklingen inom kommunalförvaltningen. Länsförbunden bistod på motsvarande sätt med råd och dåd i både förvaltningsärenden och kommunaltekniska frågor.

På I950-och I960-talen byråkratiserades och professionaliserades de kommunala förvaltningarna alltmer. Storkommunreformen I 952 skapade större landskommunala enheter både till folkmängd och yta och därmed ökad administration. En förutsättning för reformerna kan ha varit att det fanns en kommunaltjänstemannatradition att bygga vidare på. Vid mitten av I950-talet beslöt riksdagen dessutom att de tidigare särskilda stadsstadgorna skulle vara nationella stadgor gällande i alla kommuner. Byggnation, brandförsvar, hälsovård och ordning blev därmed stadigt återkommande ärenden även på landskommunernas dagordningar. De kommunala uppgifterna växte dock inte bara genom statliga direktiv utan även genom egna initiativ. Fritid, sport och kultur är några exempel på sådana områden som kommunerna började engagera sig i.

I takt med att utbildningsnivån generellt höjdes i hela riket ökade den också på kommunalkontoren. Socialassistenter och kommunalkamrerare hämtades i ökad omfattning från socialinstituten. Samtidigt fanns säkert länge i mindre kommuner på landet fortfarande många dugliga och kompetenta tjänstemän som var självlärda och hade folkskola som högsta formella utbildning.

Inspirerad av de politiska partiernas kursgårdar och med tysk förebild startade Landskommunernas förbund 1954 tillsammans 
med Stadsförbundet Kommunskolan. Den placerades i Sigtuna och där ordnades kortare och längre kurser för såväl förtroendevalda som tjänstemän. Skolan kompletterade Stadsförbundets brevkurser. Kommunförbundet, som bildades I 968, fortsatte med kursverksamheten. Mer än två av tre chefstjänstemän och kommunstyrelseordförande deltog i slutet av I980-talet i minst en av förbundets kurser och konferenser. På I970- och I980-talen gavs exempelvis kurser i lokal näringspolitik. Även för dagens organisation, Sveriges Kommuner och Landsting, är kurs- och konferensverksamhet en viktig angelägenhet. Under april 2015 ordnades till exempel över 30 kurser på olika platser i riket, bland annat den årligen återkommande demokratidagen.

I städerna växte den kommunala byråkratin alltmer. Inslaget av akademiskt skolad personal fortsatte att öka, och tjänstemännen blev snart experter inom sina områden med större kunskaper än de folkvalda. I den mån kommunerna saknade egen kompetens kunde externa konsultbyråer anlitas för olika uppdrag. Tjänstemän och externa specialister med sin höga kompetens $i$ sakfrågor upplevdes ibland som ett hot mot den kommunala demokratin. Politikerna kunde i trängda lägen försvara sig med att de var fångna i experternas garn. För att hantera den situationen räckte det inte i längden med arvoderade politiker. De folkvalda skaffade sig därför en grupp av så kallade politiska tjänstemän som ett slags filter mellan sig och kommunaltjänstemännen. På så sätt skulle frågorna kunna få en utgång som de folkvalda lättare kunde försvara.

\section{Sammanfattning}

För att bevara och vidareutveckla det kommunala självstyret är det nödvändigt med en välutbildad och kompetent personalstyrka. Det gamla idealet med oavlönade förtroendevalda som även sköter förvaltningen är sedan länge övergivet. Med växande uppgifter behövde städerna snart anställa folk både på kontoret och ute i verksamheterna. Genom sina organisationer började kommunerna under I900-talet alltmer engagera sig i utbildningsfrågor. Stadsförbundet uppmärksammade behovet av akademiker och bidrog till socialinstitutens tillkomst. Många kommunalt anställda 
inom socialvård och förvaltning har sedan dess rekryterats den vägen. Landskommunernas förbund och Landstingsförbundet inledde den rika kurs- och konferensverksamhet som sedan dess varit ett kännemärke för den kommunala sektorn, inklusive landstingen. Tidskrifter, rådgivning, handböcker och cirkulär har varit andra medel som framgångsrikt använts för att informera förbundens medlemmar om det senaste inom den kommunala utvecklingen.

Den allmänt höjda utbildningsnivån märks naturligtvis både bland politiker och bland tjänstemän i kommunerna, liksom på alla andra håll i samhället. Den ökade kompetensen bland de kommunalt anställda har samtidigt upplevts som ett hot mot den lokala demokratin. Politikerna har dock fortfarande sista ordet. Och avgörande för alla de ledamöter som valts till uppdrag i kommunala fullmäktigeförsamlingar, styrelser och nämnder är att man har folkets förtroende.

Staten har försökt garantera den kommunala kompetensen via krav på vilka nämnder som skall finnas och i vissa fall periodvis preciserat vilka befattningar som skall ingå. Vidare har staten genom länsstyrelserna och andra länsorgan velat försäkra sig om att kommunerna sköter sitt uppdrag, men även vid behov ge råd. Den statliga kontrollen har samtidigt växlat över tid och därmed utrymmet för kommunalt självstyre. Statens förtroende för kommunerna visar sig bland annat i det växande kommunala uppdraget. Det kommunala handlingsutrymmet bestäms dock inte enbart av staten utan här finns också aktörer som privata företag och EU tillsammans med strukturella krafter i samhället.

\section{Noter}

I. Lars Nilsson \& Håkan Forsell, I 50 år av självstyrelse: kommuner och landsting i förändring, (Stockholm 2013). Se även: Peter Aronsson, Thord Strömberg \& Lars Nilsson (red.), Storkommunreformen I952: striden om folkhemmets geografi (Stockholms 2002); Mats Hayen, Ett sekel $i$ självstyrelsens tjänst: Sveriges kommuner och landsting I 00 år (Stockholm 2008); www.ortshistoria.se.

2. Allmänna rådstugan var stadens högsta politiska organ dit alla röstberättigade hade tillträde. Den leddes av borgmästaren, som ansvarade för den lokala förvaltningen, men utsågs av regeringen. 
Allmänna rådstugan motsvarades på landet av sockenstämman och dess efterföljare kommunalstämman. Rådstugans, stämmans och borgmästarnas betydelse och kommunala befogenheter minskade successivt för att helt upphöra på I950-talet. Titeln borgmästare levde dock officiellt kvar fram till kommunreformen I97 I. Inofficiellt använder vissa kommuner fortfarande titeln borgmästare i samband med internationella kontakter.

3. Överståthållaren var statens representant i Stockholms kommunala förvaltning och motsvarades i övriga Sverige av länens landshövdingar. Ämbetet avvecklades i samband med I970-talets kommunreform, då Stockholms stad upphörde som eget län och lades samman med Stockholms län. 